\title{
A New Record of Campylaspis fusiformis (Crustacea: Cumacea: Nannastacidae) from Korea
}

\author{
Chang-Mok Lee ${ }^{1}$, Soon-Sang Hong ${ }^{2}$, Kyung-Sook Lee ${ }^{2, *}$ \\ ${ }^{1}$ Munsandong Middle School, Paju 413-904, Korea \\ ${ }^{2}$ Department of Life Sciences, Dankook University, Cheonan 330-714, Korea
}

\begin{abstract}
This study dealt with cumacean specimens collected from the shallow waters of the South Sea and East Sea, Korea. Campylaspis fusiformis Gamô, 1960 belonging to the family Nannastacidae is newly recorded to Korean fauna. This species resembles $C$. pumila and $C$. striata in having a similar body form and a pair of narrow lateral sulcuses on the carapace, but it is easily distinguished from them by the dactylus of the pereopod 2 which is more than 3.5 times the length of the propodus and bears many setae (about 20) on the surface. This species mainly occurs in the Korean and Japanese waters.
\end{abstract}

Keywords: Cumacea, Nannastacidae, Campylaspis fusiformis, Korea, new record

\section{INTRODUCTION}

The genus Campylaspis belonging to the family Nannastacidae, which is composed of 17 genera (Băcescu, 1992), is the largest group. Campylaspis contains about 123 species and has a wider horizontal and vertical distribution over the world than other genera (Băcescu, 1992; Watling and McCann, 1997; Petrescu, 1997). Recently, 19 new species from eastern Bass Strait, the south-eastern Australian slope and Antarctica were reported by Petrescu (2006). In Korea, only two species (Campylaspis orientalis Calman, 1911 and C. pumila Gamô, 1960) of Campylaspis have been recorded until now (Calman, 1911; Lee and Lee, 1999). In this paper, Campylaspis fusiformis Gamô, 1960 is described and illustrated as new to Korean fauna.

A light-trap was used to collect specimens from the shallow waters of the South sea and East sea of Korea between 1994-2001. Drawings and measurements were performed with the aid of a drawing tube equipped on a light microscope. Body length was measured from the anterior tip of the carapace to the posterior end of the last abdominal segment. Lengths of appendages were measured along the mid-line of each appendage, exclusive of the inflated outer angle.

\section{SYSTEMATIC ACCOUNTS}

Order Cumacea Kröyer, 1846

Family Nannastacidae Bate, 1866

Genus Campylaspis Sars, 1865

1* Campylaspis fusiformis Gamô, 1960 (Figs. 1, 2)

Campylaspis fusiformis Gamô, 1960: 370, figs. 3, 4; 1963 :

87; 1967: 257; Băcescu, 1992: 187.

Material examined. Korea: Gangwon-do: $1 \sigma^{\top}$, Samcheoksi, Samcheok Port, 6 Aug 1994, Kang BJ; 1 ð , Donghae-si, Donghae Port, 21 Aug 2001, Lee CM; Jeollanam-do: $1 \overbrace{}^{7}$, Wando-gun, Isl. Cheongsando, 21 Aug 2001, Lee CM.

Male: Body (Fig. 1A) calcified, $3.7 \mathrm{~mm}$ in length, excluding uropods, Carapace (Fig. 1A-C) vaulted, slightly longer than $1 / 3$ body length, 1.6 times longer than wide, 2.3 times longer than deep, with 8-10 pairs of pellucid spots on anterodorsal portion, 1 pair of narrow sulcus on lateral portion; surface faintly pitted; antennal notch shallowly concave, anterolateral corner obtuse and smooth; pseudorostral lobes not truncate, subequal to length of ocular lobe; ocular lobe round, with 3 lenses.

Antenna 1 (Fig. 1D). Peduncle 3-articulated; first article
(C) This is an Open Access article distributed under the terms of the Creative Commons Attribution Non-Commercial License (http://creativecommons.org/ licenses/by-nc/3.0/) which permits unrestricted non-commercial use, distribution, and reproduction in any medium, provided the original work is properly cited.

pISSN 2234-6953
*To whom correspondence should be addressed

Tel: 82-70-7154-2248, Fax: 82-41-599-7861

E-mail: kslee@dankook.ac.kr

Korean name: ${ }^{1 *}$ 고랑꼬마올챙 이새 우(신칭) 


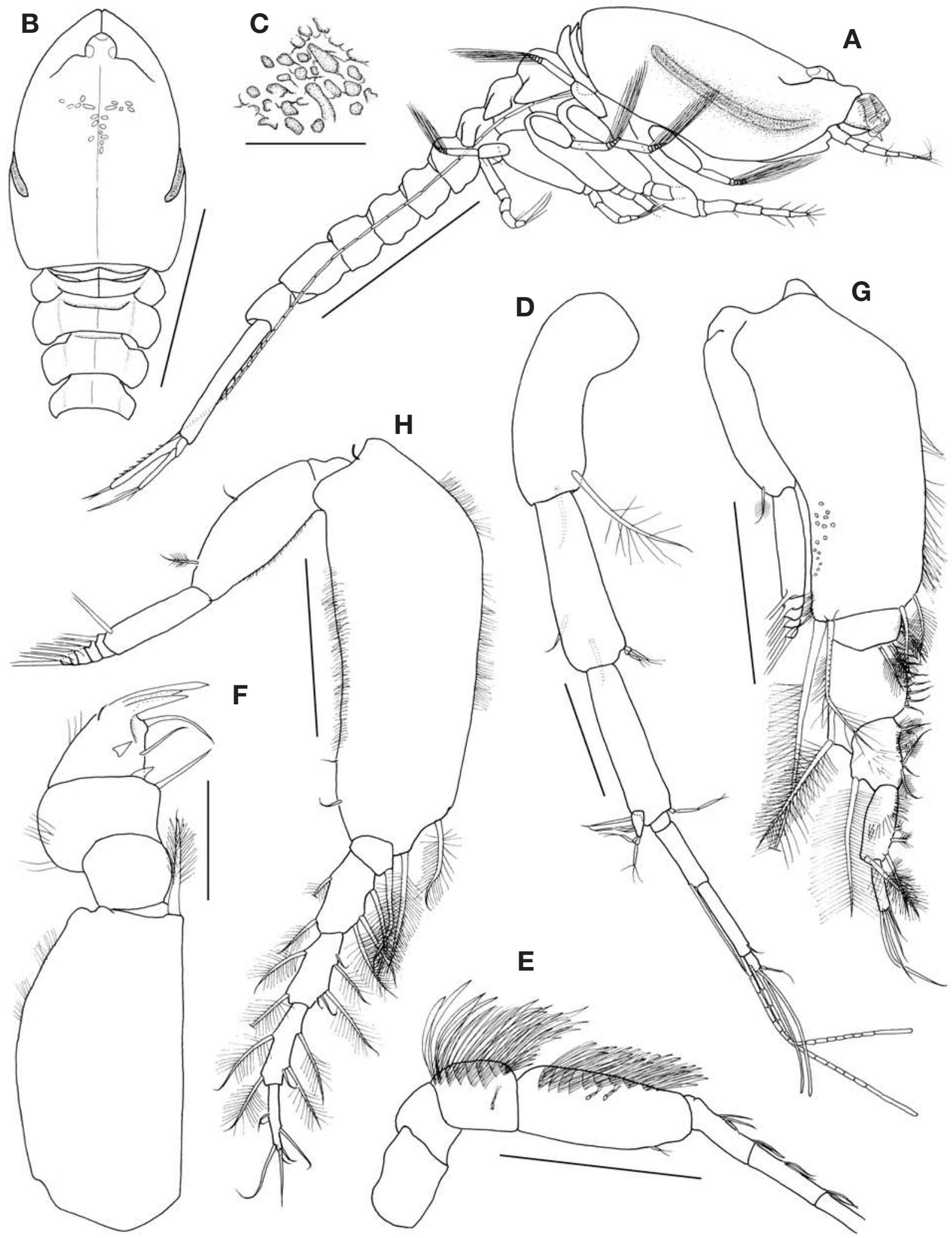

Fig. 1. Campylaspis fusiformis, male. $A$, Habitus, lateral; $B$, Cephalothorax, dorsal; $C$, Surface of carapace; $D$, Antenna 1 ; $E$, Antenna 2; F, Maxilliped 2; G, Maxilliped 3; H, Pereopod 1. Scale bars: A, B=1 mm, C, D, F=0.1 mm, E, G, H=0.3 mm. 


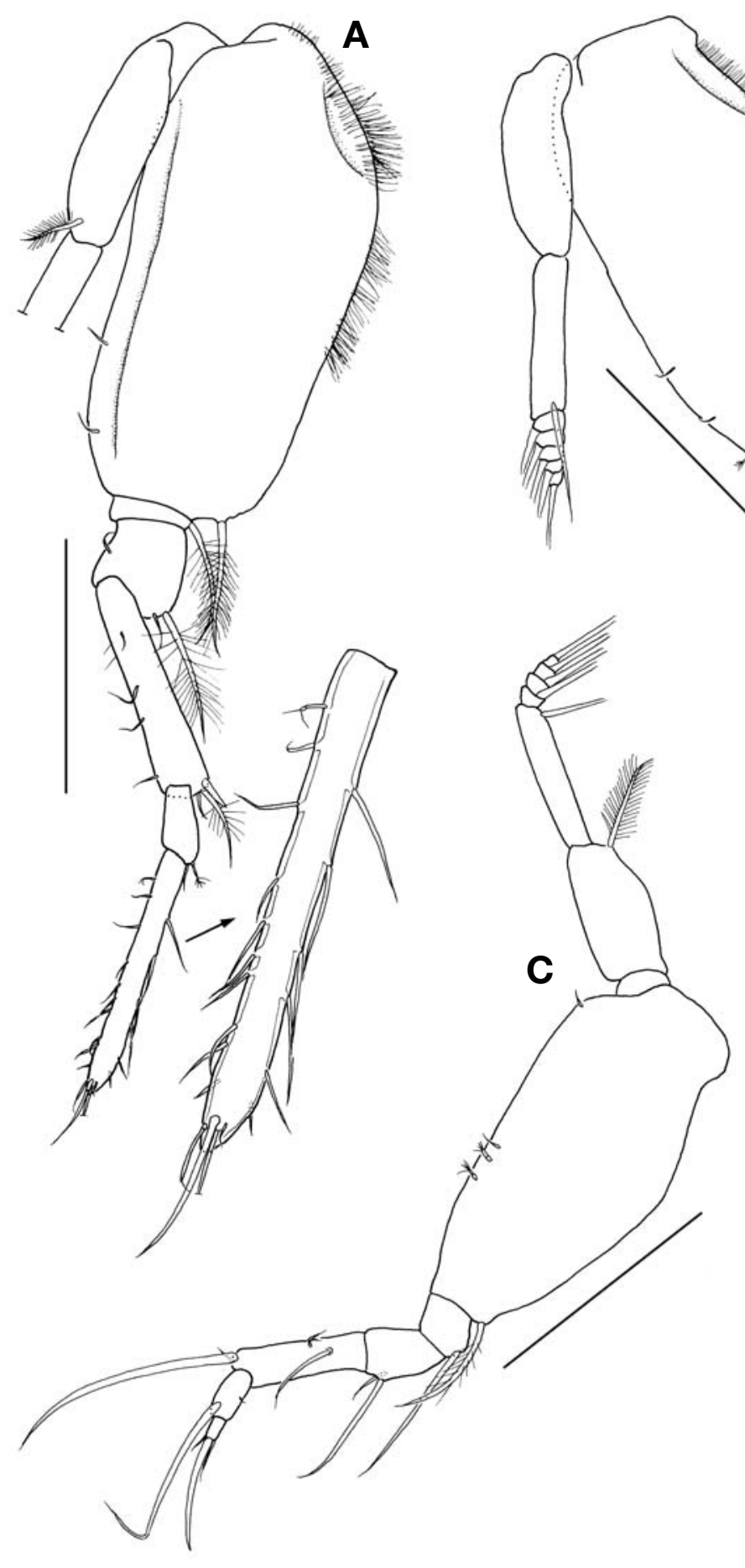

B
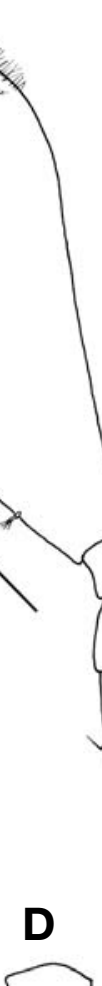

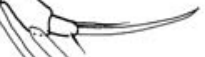

$\mathbf{E}$
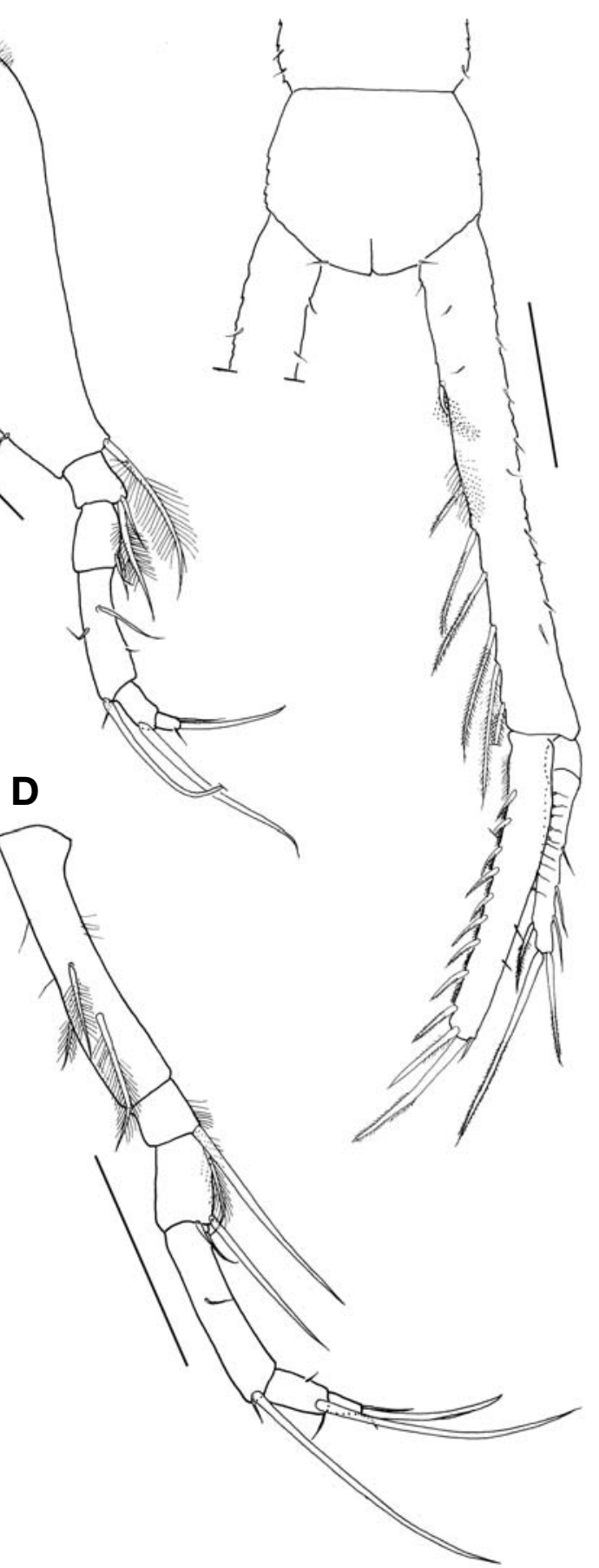

Fig. 2. Campylaspis fusiformis, male. A, Pereopod 2; B, Pereopod 3; C, Pereopod 4; D, Pereopod 5; E, Uropod and pleonite 6, dorsal. Scale bars: $A-C, E=0.3 \mathrm{~mm}, D=0.2 \mathrm{~mm}$.

slightly longer than second one, with 1 simple and 1 plumose setae near inner corner; second article with 2 simple and 2 sensory setae near distal margin; third article slightly shorter than second one, with 1 sensory seta on inner corner. Main flagellum 4-articulated; third article very long, with 1 short seta and 1 aesthetasc near distal margin; fourth arti- 
cle subequal to $1 / 4$ length of third one, with 1 aesthetasc, 1 sensory and 2 long simple setae near terminal margin. Accessory flagellum uniarticulated, slightly longer than fourth article of main flagellum, with 3 simple and 2 sensory setae.

Antenna 2 (Fig. 1A, E) very long, extending beyond uropodal peduncle. Peduncle 4 -articulated; third article with 1 short sensory seta and 9 rows of long sensory setae on surface; last article with 3 short sensory setae and 10 rows of long sensory setae on surface.

Thorax (Fig. 1A) 0.55 times as long as carapace length and slightly longer than $1 / 5$ body length. Abdomen 0.6 times as long as cephalothorax length.

Maxilliped 2 (Fig. 1F). Basis two times longer than wide, with 1 strong pappose seta on inner corner; dactylus with 3 spiniform setae on terminal margin.

Maxilliped 3 (Fig. 1G). Basis slightly longer than remaining articles combined, with numerous hair-like setae on inner margin, 2 plumose setae on inner corner, 2 plumose setae and 1 short simple seta on outer corner; merus with several teeth and 8-9 simple setae on inner margin.

Pereopod 1 (Fig. 1H). Basis 1.12 times as long as remaining articles combined, with 2 plumose setae distally on inner margin, 2 short simple setae distally on outer margin; carpus 0.9 times as long as propodus, with 2 plumose, 3 short simple setae on inner margin, 2 plumose setae on outer margin.

Pereopod 2 (Fig. 2A). Basis 0.75 times as long as remaining articles combined, with 1 plumose seta on inner corner, 2 short simple setae on outer margin distally; dactylus 3.8 times as long as propodus, with 10 simple setae on inner margin, 6 simple setae on outer margin, terminal margin pointed, with 1 short and 3 long simple setae.

Pereopod 3 (Fig. 2B). Basis 1.7 times as long as remaining articles combined.

Pereopod 4 (Fig. 2C). Basis 1.25 times as long as remaining articles combined.

Pereopod 5 (Fig. 2D). Basis 0.7 times as long as remaining articles combined.

Uropod (Fig. 2E). Peduncle 2.7 times as long as pleonite 6, with 2 plumose and 6 pectinated setae on inner margin; endopod uniarticulated, 0.6 times as long as peduncle length; inner margin serrated, with numerous hair-like setae, 9 spiniform setae; outer margin with 12 short sensory setae; terminal margin with 1 short simple seta, 2 pectinated setae; exopod biarticulated, 0.7 times as long as endopod, with 1 pectinated seta on inner margin; outer margin with 3 simple setae; terminal margin with 2 pectinated setae.

Remarks. Campylaspis fusiformis is similar to C. pumila Gamô, 1960 and C. striata Gamô, 1960 in having a similar body form and a pair of narrow lateral sulcuses on the carapace. However, C. fusiformis can clearly be distinguished from $C$. pumila and C. striata by the length of the dactylus of pereopod 2 and the armature of the uropodal endopod: 1 ) the dactylus of the pereopod 2 is more than 3.5 times the length of the propodus in C. fusiformis, while less than 3 times the length in $C$. pumila and $C$. striata; 2) the uropodal endopod has 9 setae on the inner margin in C. fusiformis, but has 7 setae in $C$. striata. Moreover, the dactylus of the pereopod 2 has about 20 seate on the surface in $C$. fusiformis, while it has 11 setae in C. pumila and 13 setae in $C$. striata.

Our male specimens agree well with the original description of Campylaspis fusiformis by Gamô (1960) from the Japanese waters. However, a few differences are found between ours and the type specimen. The uropodal peduncle has 2 plumose and 6 pectinated setae on the inner margin in our male specimens, while it has 2-3 serrations and 5 plumose setae in the type specimens. Also, the surface of the carapace is faintly pitted in our specimens, while this feature is not mentioned in Gamô's original description.

Distribution. Korea (South Sea, East Sea) and Japan.

\section{ACKNOWLEDGMENTS}

This work was supported by the Flora and Fauna Project of Korea (2010), National Institute of Biological Resources (NIBR) under the Ministry of Environment, Korea.

\section{REFERENCES}

Băcescu M, 1992. Cumacea II (Fam. Nannastacidae, Diastylidae, Pseudocumatidae, Gynodiastylidae et Ceratocumatidae). Crusaceorum Catalogus Pars, 8:175-468.

Calman WT, 1911. On new or rare Crustacea of the order Cumacea from the collection of the Copenhagen Museum-part. Part II. The families Nannastacidae and Diastylidae. Transactions of the Zoological Society of London, 18:341-398.

Gamô S, 1960. On six new species of cumacean Crustacea, genus Campylaspis (Nannastacidae) from Japan. Zoological Magazine, 69:369-387.

Gamô S, 1963. Review summary on the order Cumacea, with a list of the species found in Japan. Researches in Crustacea, Carcinological Society of Japan, Tokyo, 1:73-90.

Gamô S, 1967. Studies on the Cumacea (Crustacea, Malacostraca) of Japan. Part 2. Publications of the Seto Marine Biological Laboratory, 15:245-274.

Lee CM, Lee KS, 1999. Cumacean Fauna of southern coast and Chejudo Island in Korea. Korean Journal of Systematic Zoology, 15:83-105.

Petrescu I, 1997. Cumacea. Travaux du Museum National d'Histoire Natuelle "Grigore Antipa", 38:115-175.

Petrescu I, 2006. Nannastacidae (Crustacea: Cumacea) from 
eastern Bass Strait, the south-eastern Australian slope, and Antarctica in the collections of Museum Victoria. Memoirs of Museum Victoria, 63:129-173.

Watling L, McCann LD, 1997. Cumacea. Taxonomic atlas of the benthic fauna of the Santa Maria Basin and western Santa Barbara Channel. Santa Barbara Museum of Natural
History, 11:121-180.

Received October 31, 2011

Revised December 19, 2011 Accepted December 26, 2011 